\title{
Spotlight on the August 24 Issue
}

Robert A. Gross, MD, PhD, FAAN

Editor-in-Chief, Neurology ${ }^{\circledR}$

\section{Health state preferences and decision-making after malignant middle cerebral artery infarctions \\ (0)}

Surgical decompression improves outcomes after malignant MCA infarctions, but many survivors remain significantly disabled. In this decision analysis, surgery resulted in more quality-adjusted life-years than medical management except when possible outcomes were valued as very poor. How patients/families value expected outcomes is a critical component to decision-making in stroke.

See p. 682; Editorial, p. 676

Aspirin and recurrent intracerebral hemorrhage in cerebral amyloid angiopathy

This single-center prospective cohort study enrolled 104 primary lobar intracerebral hemorrhage survivors. The authors found that aspirin use in patients with cerebral amyloid angiopathy was associated with increased risk of recurrent hemorrhage. Caution may be warranted in using antiplatelet agents in individuals with cerebral amyloid angiopathy. See p. 693

Referral pattern for epilepsy surgery after evidence-based recommendations: A retrospective study

$\mathrm{Pt}$

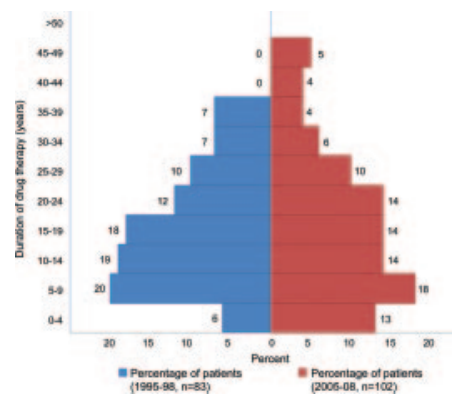

The authors compared referral data for patients with temporal lobe epilepsy during two 3-year periods: 1995-1998 and 20052008. This showed that surgical treatment for epilepsy is underutilized, and potential candidates are referred too late to

avoid irreversible psychological and social disability.

See p. 699, Editorial 678

From this issue's Patient Page: "Now that clinical practice guidelines (CPGs) for doctors have been established, the next challenge is creating ways to successfully apply CPGs to treatment decisions."

See p.e41
AMERICAN ACADEMY OF NEUROLOGY。

\section{Cognitive consequences of childhood-onset temporal lobe} epilepsy across the adult lifespan

Neuropsychological profiles of 382 patients with childhoodonset medically intractable seizures associated with unilateral hippocampal sclerosis showed that the profile of cognitive deficits associated with mesial temporal lobe epilepsy was already established in temporal lobe epilepsy when patients entered adulthood.

See p. 705

An unfavorable lifestyle and recurrent headaches among adolescents: The HUNT Study

This cross-sectional study consisted of 5,847 student interviews about their headache complaints. Being overweight, smoking, or low physical activity were associated with recurrent headache among adolescents. Change of lifestyle may prevent headache in this age group.

See p. 712; Editorial, p. 680

\section{The burden of inherited leukodystrophies in children} in

The authors identified 664 children with a possible leukodystrophy, of whom 122 patients met inclusion criteria. Inherited leukodystrophies were associated with substantial morbidity and mortality, with an overall population incidence higher than generally appreciated. Most leukodystrophies remain undiagnosed, but a logical algorithm based on prevalence should aid testing.

See p. 718

\section{SPECIAL ARTICLE}

Invited Article: Improving safety for the neurologic patient: Evaluating medications, literacy, and abuse

This article discusses the effect of medication errors, health literacy, and abuse and neglect. The best approach since 2004 has been to incorporate, at the beginning of neurology training, patient safety education and formal training in abuse and neglect.

See p. 742

NB: "Are epilepsy surgery guidelines being followed?" and other Patient Pages

See p. e41

Podcasts can be accessed at www.neurology.org 


\title{
Neurology
}

\author{
In Focus: Spotlight on the August 24 Issue \\ Robert A. Gross \\ Neurology 2010;75;675 \\ DOI 10.1212/WNL.0b013e3181f18238
}

This information is current as of August 23, 2010

Updated Information \&

Services

Permissions \& Licensing

Reprints including high resolution figures, can be found at: http://n.neurology.org/content/75/8/675.full

Information about reproducing this article in parts (figures,tables) or in its entirety can be found online at:

http://www.neurology.org/about/about_the_journal\#permissions

Information about ordering reprints can be found online:

http://n.neurology.org/subscribers/advertise

Neurology ${ }^{\circledR}$ is the official journal of the American Academy of Neurology. Published continuously since 1951, it is now a weekly with 48 issues per year. Copyright. All rights reserved. Print ISSN: 0028-3878. Online ISSN: 1526-632X.

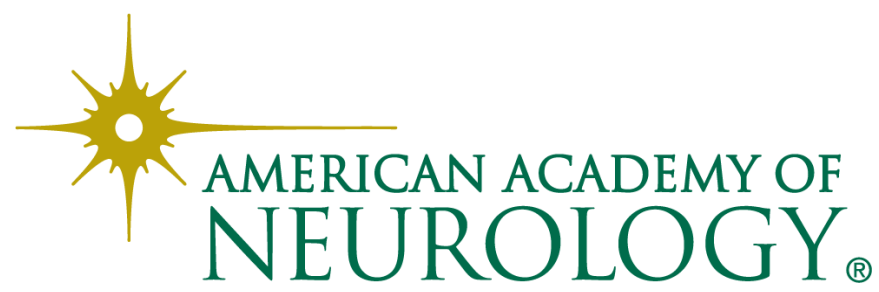

